\title{
Neglected Intussusception Presenting as Transanal Prolapse of Small Bowel
}

To the Editor: I read with great interest the article by Ray et al., demonstrating the management of a neglected and unusual case of intussusceptions [1]. I congratulate the author and his team for managing the case referred too late to their institute.

Usually the diagnosis of intussusception is made on clinical basis and very rarely it may require imaging. In developing countries like us with limited resources, lack of adequate knowledge and poverty, delayed presentation is quite common. Atypical presentation can delay the diagnosis resulting in increased morbidity. As early features might not be typical of intussusception, a high index of suspicion is necessary to avoid confusion with rectal prolapse. So in every case of rectal prolapse in children, detail clinical examination including both per rectal and per abdominal examination is mandatory. In case of any doubt, easily available imaging like USG can be done so that a treatable disease should not be neglected.

Regarding surgical management of the case described by the authors, it is always better to do resection of gangrenous bowel with proximal and distal diversion rather than anastomosis of bowel. These cases are usually chronic and even normal bowel is edematous and hypertrophied. So staged procedure should be done to decrease further morbidity.

S. S. Panda $(\square)$ Department of Pediatric Surgery, All India Institute of Medical Sciences, New Delhi 110029 India e-mail: drshasank_aiims@yahoo.co.in

\section{References}

1. Ray A, Mandal KC, Shukla RM, Roy D, Mukhopadhyay B, Bhattacharya M. Neglected Intussusception Presenting as Transanal Prolapse of Small Bowel. Indian J Pediatr. 2012;79:1370-1.

\section{Authors' Reply}

To the Editor: We would like to thank the authors for their nice comments. The main purpose of writing this article was to aware the general physicians as well as junior pediatricians regarding the importance of early diagnosis of intussusception. Intussusception may be confused with bacillary dysentery with bleeding per rectum if you do not palpate the abdomen of the child. In case of transanal prolapse of intussusception, it can be easily diagnosed by a digital rectal examination as mentioned in the article.[1] If you fail to diagnose intussusception early then the morbidity and mortality is increased considerably.

A. Ray: K. C. Mandal: R. M. Shukla: B. Mukhopadhyay:

M. Bhattacharya

Department of Pediatric Surgery,

Nil Ratan Sircar Medical College and Hospital,Kolkata, India

D. Roy

Department of Pediatric Surgery, BC Roy Post-Graduate Institute of Pediatric Sciences, Kolkata, India

$$
\begin{array}{r}
\text { R. M. Shukla (乔 } \\
\text { 7E, Dinobandhu Mukherjee Lane, Sibpur } \\
\text { Howrah } 711102 \text { West Bengal, India } \\
\text { e-mail: rammohanshukla@yahoo.co.in }
\end{array}
$$

\section{References}

1. Ray A, Mandal KC, Shukla RM, Roy D, Mukhopadhyay B, Bhattacharya M. Neglected Intussusception Presenting as Transanal Prolapse of Small Bowel. Indian J Pediatr. 2012;79:1370-1. 